\title{
EDUCAÇÃO AMBIENTAL E CONTEXTO ESCOLAR: QUESTÕES PARA UM PROGRAMMA DE PESQUISAS
}

\author{
Maria Jacqueline Girão Soares de Lima ${ }^{1}$ \\ Luiz Marcelo de Carvalho ${ }^{2}$
}

Resumo: Neste artigo, sistematizamos as discussões realizadas pelo (GDP) "Pesquisa em EA e Contexto Escolar", no VII EPEA, que tiveram, como eixo principal, temáticas, autores e perspectivas teóricas privilegiados nas pesquisas apresentadas no evento e que se autodeclararam filiadas a esse GDP. O diálogo com pesquisas de encontros anteriores e outras visa aprofundar as questões postas pelas pesquisas do grupo. As discussões permitiram identificar temas e questões que se apresentam como significativas e desafiadoras para a pesquisa em EA no contexto escolar, a saber: a conversão das escolas em espaços educativos sustentáveis; as parcerias público-privadas, com o grande interesse de empresas e ONGs nos espaços escolares, que acenam com kits de materiais didáticos produzidos para a escola; a falta de investimentos em políticas públicas de formação de professores em EA; certa tendência a uma adesão à educação ambiental crítica, sem, no entanto, ter claros os compromissos teóricometodológicos decorrentes dessa opção.

Palavras-chave: Pesquisa em Educação ambiental. Educação escolar. Grupo de discussão de pesquisa.

\section{ENVIRONMENTAL EDUCATION AND SCHOOL CONTEXT: ISSUES FOR A RESEARCH PROGRAM}

Abstract: In this paper are systematized the discussions conducted by GDP "Research in EA and School Context", in VII EPEA, which have had, as its main axis, themes, authors and theoretical perspectives privileged in research presented at the event and declared themselves affiliated to this GDP. The dialogue with researches from previous meetings and other, aims to deepen the questions posed by the research group. The discussions allowed to identify themes and issues that present themselves as significant and challenging for research in EA in the school context, namely the conversion of schools into sustainable educational spaces; public-private partnerships, with great interest from companies and NGOs in school spaces, waving kits with educational materials produced for the school; lack of investment in public policies for teacher training in EA; tendency to an adherence to critical environmental education, without, however, have clear theoretical and methodological commitments under this option.

Keywords: Environmental Education. Research.School. EA Research.

\footnotetext{
${ }^{1}$ Professora Adjunta, do Departamento de Didática, Faculdade de Educação da Universidade Federal do Rio de Janeiro (UFRJ), Rio de Janeiro, Brasil, jaclima@ centroin.com.br

2 Professor Assistente Doutor, Departamento de Educação, Instituto de Biociências, da Universidade Estadual Paulista "Júlio Mesquita Filho" (UNESP) Campus de Rio Claro, São Paulo, Brasil, lmarcelo@rc.unesp.br
} 


\section{EDUCACIÓN AMBIENTAL Y EL CONTEXTO ESCOLAR: CUESTIONES PARA UN PROGRAMA DE INVESTIGACIÓN}

Resumen: En este artículo se sistematizan los debates celebrados por el GDP "La investigación en EA y Contexto Escolar", en el VII EPEA, que tenía, como su eje principal, temas, autores y perspectivas teóricas privilegiados en las investigaciones presentadas en el evento y se auto-declararon afiliados a este GDP. El diálogo con las investigaciones de las reuniones anteriores y otras busca profundizar las preguntas formuladas por el grupo. Las discusiones ayudaron a identificar temas y cuestiones que se presentan como significativas $y$ estimulantes para la investigación en EA en el contexto escolar, es decir, la conversión de las escuelas en espacios educativos sostenibles; cooperación público-privadas, con gran interés por parte de las empresas y las ONG en los espacios escolares, ondeando con kits con materiales educativos producidos para la escuela; falta de inversión en políticas públicas para la formación de profesores en EA; tendencia a la adhesión a la educación ambiental crítica, sin, todavía, tener claros los compromisos teóricos y metodológicos bajo esta opción.

Palabras clave: Investigación en Educación Ambiental. Educación Escolar. Grupos Focales de Investigación.

\section{Introdução}

Os Encontros de Pesquisa em Educação Ambiental (EPEAs) reúnem, a cada dois anos, desde 2001, estudantes, professores e pesquisadores de todo o Brasil interessados nesse tema. Algumas pesquisas do tipo Estado da Arte ou estudos que procuram explorar e mapear tendências, temáticas, grupos de pesquisa e perspectivas teóricometodológicas em diálogos e disputas no campo da pesquisa em EA têm revelado o impacto, a grande representatividade e o acúmulo de reflexões que esse evento tem proporcionado para o campo em nosso país (CAVALARI; SANTANA; CARVALHO, 2006; KAWASAI et al., 2009; RINK; MEGID, 2009; CARVALHO; FARIAS, 2010).

Dentre as diversas atividades para a discussão da pesquisa em EA, os Grupos de Discussão de Pesquisa organizados a partir de temáticas que se mostram significativas, quando consideramos o conjunto de trabalhos que têm sido apresentados no evento, têm despertado um grande interesse dos participantes do encontro. $\mathrm{Na}$ sétima edição do EPEA, o GDP Pesquisa em Educação Ambiental no Contexto Escolar, que vem se reunindo desde 2003, mais uma vez foi proposto como um espaço para acompanhamento das tendências teórico metodológicas das pesquisas em EA que têm como foco a escola.

As discussões nesse GDP, como de praxe, tiveram como eixo principal os trabalhos aceitos para apresentação e publicação nos Anais do evento que, quando de sua inscrição, filiaram o trabalho encaminhado a essa temática. Ao recebermos os trabalhos vinculados a esse GDP, como coordenadores do grupo procuramos destacar e apresentar para os participantes dos dois encontros previstos na programação do evento as temáticas, autores e perspectivas teóricas privilegiadas nas pesquisas, elencando, a partir desse quadro, questões para o debate, em diálogo com pesquisas de encontros anteriores e outras, divulgadas em outros espaços de socialização do conhecimento 
produzido sobre o tema. Além disso, como orientação para os trabalhos do grupo, recuperamos debates do GDP dos encontros anteriores, registrados nas publicações do grupo no periódico Pesquisa em Educação Ambiental.

Face aos inúmeros desafios colocados para a escola em relação à Educação Ambiental, buscamos sistematizar um conjunto de questões que pudessem nortear um programa interinstitucional de pesquisas, conforme indicamos em Guido, Lima e Carvalho (2012).

Na próxima seção, apresentamos um relato da dinâmica do GDP, iniciando pela enunciação das temáticas e autores dos trabalhos aceitos para publicação, seguido pelo debate propriamente dito. Uma vez evidenciada, de um lado, a pequena participação nos dois encontros do grupo dos pesquisadores autores das pesquisas vinculadas ao GDP e, de outro, a presença de muitos professores interessados em se apropriar das teorizações do campo da EA, nossa opção, neste artigo, foi a de detalhar os debates e discussões realizadas, reveladoras de discursos diversos, em movimentos de articulação. Os debates foram, então, o ponto forte do GDP e orientaram a seleção das questões priorizadas como mais significativas para compor este texto. Nas considerações finais, tecemos comentários a partir de um resumo das questões debatidas nos encontros do grupo, em diálogo com nosso referencial teórico e com pesquisas apresentadas no GDP, elencando questões que consideramos frutíferas para um programa interinstitucional de pesquisas em educação ambiental nos contextos escolares.

\section{A dinâmica do GDP e os trabalhos}

Tradicionalmente, O GDP Pesquisa em EA e Contexto Escolar é o que apresenta o maior número de trabalhos a ele associados. Os trabalhos anteriormente mencionados, que têm se voltado para estudos do estado da arte da educação ambiental no Brasil, têm apontado para a tendência de uma maior concentração de pesquisas que se voltam para o contexto escolar (KAWASAKI et al., 2009; RINK; MEGID, 2009; CARVALHO; FARIAS, 2010). Possivelmente, essa tendência de privilegiar o espaço escolar como foco para suas investigações está relacionada com a valorização e o reconhecimento, pelos pesquisadores, da função social e educativa da escola, principalmente em países com alta desigualdade social, como o Brasil. Muitos desses pesquisadores, professores da educação básica e membros de instituições, públicas e privadas, que atuam direta ou indiretamente na educação formal e não formal, entendem ser a escola o lugar possível para a construção de um capital cultural, tarefa que deixa de ser cumprida por boa parte das famílias brasileiras e pela ausência de espaços educativos múltiplos. Nesse encontro, um total de vinte e sete trabalhos que tomaram o contexto escolar como foco de suas investigações, correspondendo a quase $1 / 3$ do total de trabalhos aprovados pela comissão científica do evento, foram aceitos para apresentação e publicação.

O grupo de 22 pessoas foi constituído, principalmente, por professores da escola básica com pouca inserção na pesquisa acadêmica (algo comum nos EPEAs e, mais especificamente, no grupo de contexto escolar). Apenas cinco autores de trabalhos publicados nos Anais estiveram presentes, o que nos levou, como já mencionado, a optar por uma dinâmica mais focada nos debates sobre as questões norteadoras do que nas pesquisas apresentadas no encontro e vinculadas pelos autores ao GDP. Acreditamos que o baixo número de autores presentes nas reuniões do GDP esteja ligado à exigência dos programas de pós-graduação em relação à publicação de trabalhos em eventos de pesquisa, que tem se mostrado incompatível com as 
dificuldades enfrentadas pelos professores para dispensa do trabalho e com a carência de recursos dos programas para financiar a participação nos mesmos. ${ }^{3}$ Em compensação, algumas prefeituras têm oferecido condições para seus professores participarem do encontro, como atividade de formação continuada. Assim, o perfil dos participantes desse GDP tem sido, cada vez mais, de professores da escola básica.

Com o intuito de oferecer um quadro geral dos trabalhos vinculados ao GDP pelos seus autores, no que diz respeito às temáticas dos trabalhos publicados e possíveis ênfases a partir dessas temáticas, a coordenadora do GDP preparou uma tabela que foi apresentada aos participantes (Tabela 1) no início dos trabalhos. Essa apresentação também foi pensada como motivação para início das discussões do grupo e para o início de levantamento de questões que poderiam ser exploradas na continuidade dos trabalhos.

Tabela 1 - Temas e ênfases dos trabalhos vinculados ao GDP Pesquisa em Educação Ambiental e Contexto Escolar e publicados nos Anais do VII Encontro de Pesquisa em Educação Ambiental.

\begin{tabular}{|l|l|l|}
\hline TEMÁTICA & ÊNFASES & QUANTITATIVO \\
\hline CURRÍCULO & $\begin{array}{l}\text { Contexto local, estratégias didáticas, } \\
\text { conhecimento escolar, análise do } \\
\text { discurso. }\end{array}$ & $13(48 \%)$ \\
\hline TENDÊNCIAS NA EA & \multicolumn{1}{|c|}{$1(3.5 \%)$} \\
\hline $\begin{array}{l}\text { PARCERIAS PÚBLICO } \\
\text { PRIVADAS }\end{array}$ & & $2(7 \%)$ \\
\hline CONCEPÇÕES & Educação ambiental e meio ambiente & $9(33 \%$, duas ligadas à EJA). \\
\hline POLÍTICAS PÚBLICAS & & $1(3.5 \%)$ \\
\hline
\end{tabular}

Os dados sistematizados na Tabela 1 evidenciam a ênfase dada à temática de Currículo nos trabalhos vinculados a este GDP no VII EPEA. As pesquisas que privilegiaram essa temática enfatizaram discussões sobre contexto local, estratégias didáticas e conhecimento escolar, principalmente. Além disso, é importante ressaltar as articulações possíveis entre diferentes temáticas, como o tratamento de questões relativas ao currículo e à educação de jovens e adultos, ou articulações do campo do currículo com questões relativas a parcerias público-privadas ou políticas públicas. Merece ainda registro a utilização de perspectivas na linha da análise do discurso para estudos de currículo.

É interessante observar que autores do campo do Currículo foram citados catorze vezes nos vinte e sete trabalhos (em alguns, mais de uma vez, não somente nos trabalhos categorizados como de currículo). Ainda nessa categoria, observamos que a pesquisa $O$ que fazem as escolas que dizem que fazem Educação Ambiental?, realizada pelo INEP, em 2006, em escolas de todo o Brasil, enfocando as práticas de Educação Ambiental nas escolas, foi mencionada em cinco trabalhos. Consideramos que a predominância do tema currículo nos trabalhos e o diálogo com os autores desse campo como um avanço, pois há bastante tempo vimos questionando o pouco diálogo da Educação Ambiental com autores e discussões da Educação (LIMA, 2007, 2011; LOUREIRO; LIMA, 2006; CARVALHO, 2009). Cabe observar, no entanto, que as

\footnotetext{
${ }^{3}$ A título de comparação, lembramos que, no encontro anterior, havia 12 autores de trabalhos dentre os participantes do GDP, o que permitiu uma leitura mais produtiva dos mesmos.
} 
metodologias e conclusões dos trabalhos nem sempre estão de acordo com seus referenciais teóricos.

Outro dado que nos chamou à atenção foi a presença de três trabalhos sobre Educação Ambiental na Educação de Jovens e Adultos. Consideramos essa articulação extremamente produtiva, pois os dois campos compartilham princípios e autores, como Paulo Freire, Dermeval Saviani e autores da perspectiva CTSA (Ciência, Tecnologia, Sociedade e Ambiente), que buscam integrar o ensino das Ciências da Natureza às questões sociais e ambientais mais amplas, abordando vieses como inclusão, desigualdade, justiça social e ambiental, identidade entre outras.

Inseridas nos eixos temáticos estão pesquisas relacionadas ao tema sustentabilidade/desenvolvimento sustentável nas escolas. Fizemos uma busca nos trabalhos e obtivemos doze ocorrências para o termo sustentabilidade e catorze para o termo sustentável. A centralidade dessa temática, entretanto, é proporcional à superficialidade com a qual é tratada em muitas pesquisas. Voltamos a esse ponto nas considerações finais.

Em relação às perspectivas teórico-metodológicas que orientaram as pesquisas vinculadas ao GDP, podemos buscar algumas evidências a partir da identificação de autores referenciados nos textos. Esse dado aponta para uma predominância da vertente crítica da EA e, nesse caso, o autor mais citado foi Carlos Frederico Loureiro. Depois de Loureiro, foram bastante citados Gustavo Lima, Isabel Carvalho, Mauro Guimarães, Phillipe Layrargues, Marcos Reigota, Marília Tozzoni-Reis, Luiz Marcelo de Carvalho, Mauro Grun, Michelle Sato e Enrique Leff (não necessariamente nessa ordem). Como se pode observar, e parece-nos importante ressaltar, que autores que têm procurado outras orientações ou outras vertentes teórico-metodológicas para suas análises e reflexões, e nesse caso podemos mencionar os Estudos Culturais, também foram referenciados nos textos.

A partir dessas observações e categorizações dos trabalhos aceitos para publicação nos Anais do VII EPEA, propusemos aos participantes que, divididos em grupos, refletissem sobre três questões:

- As investigações sobre EA nos contextos escolares e a pesquisa $O$ que fazem as escolas que dizem que fazem educação ambiental (TRAJBER e MENDONÇA, 2006) indicam a forte presença da EA nas escolas brasileiras. Em termos curriculares, podemos pensar que está se criando uma EA escolar que pouco dialoga com os referenciais do campo do currículo?

- Perspectiva crítica predomina, mas... crítica de quê?

- Sentidos sobre educação ambiental, meio ambiente, educação e sustentabilidade são disputados nas políticas e pesquisas. No entanto, é comum esses termos serem tratados como se não houvesse divergências de ordem teórico-metodológicas. Como podemos avançar nesse debate?

No primeiro encontro não avançamos na discussão porque nos dedicamos a apresentar os dados dos trabalhos e as questões norteadoras do GT, a nos apresentar e a ouvir os participantes, que relataram suas experiências profissionais e acadêmicas com a Educação Ambiental. Assim, nesse primeiro encontro demos apenas início aos debates, que foram retomados no segundo encontro, com produção de relatos escritos pelos participantes.

Iniciamos a discussão partindo do pressuposto de que existe uma educação ambiental que está sendo construída tendo como endereço o espaço escolar, e que há diversas maneiras de compreender sua entrada nas escolas. A partir daí, levantamos um 
ponto abordado pelo professor Carlos Frederico Loureiro no debate ocorrido na mesa redonda daquela manhã, sobre os projetos de educação ambiental capitaneados por empresas, que chegam às escolas por meio das parcerias público-privadas. Tais projetos estão pautando currículos, práticas, formação docente e políticas públicas, questões presentes em algumas das pesquisas associadas ao grupo, como sistematizado na Tabela 1. Essa discussão foi introduzida no debate articulada aos eixos propostos no dia anterior, e cinco grupos se formaram para discutir as questões delineadas. Em cada grupo havia um autor de trabalho aprovado, pois foi sugerido pelos coordenadores que os pesquisadores refletissem, com os grupos, caminhos para o enfrentamento das questões colocadas a partir de suas pesquisas.

Um dos grupos ressaltou a carência de investimentos em politicas públicas voltadas para a formação de professores em EA. Foi mencionada, também, a questão da (falta de) autonomia das escolas e a dificuldade de se trabalhar a interdisciplinaridade nos contextos formativos e escolares. Em relação à provocação crítica de quê, o grupo argumentou que não existe uma real inserção da EA nas escolas, mas, apenas, da temática ambiental, e propõe que se trabalhe com conflitos ambientais para que a EA seja efetivamente implementada. Concluíram que a pesquisa de autoria de um dos componentes do grupo tem o potencial de contribuir para uma reflexão sobre processos de inserção da temática ambiental nos currículos dos cursos de licenciatura.

O segundo grupo propôs uma discussão sobre recursos públicos para a educação. Em relação à entrada das empresas nas escolas, afirmam que, ainda que os projetos empresariais abordem a questão ambiental, há interesses mercadológicos de cunho neoliberal. Para esse setor, a questão ambiental é vista como utopia e cabe às pesquisas desmistificar esse entendimento. Concluem que é difícil construir uma EA escolar problematizadora, e que esse é um desafio a ser enfrentado por professores e pesquisadores. Sobre a pergunta crítica de quê, afirmam que a EA que entra nas escolas através das parcerias público-privadas se caracteriza por uma crítica limitada pelos interesses do parceiro e por uma visão moralista, quando muito restrita à esfera do consumo. Essa EA desloca o espaço de produção do conhecimento, em um movimento que expropria e proletariza os docentes, que perdem o controle de sua produção curricular a partir de mecanismos de controle externos (formação, apostilas etc.).

Uma professora que trabalha na Secretaria de Educação do estado de São Paulo afirmou que, quando a escola tem um Projeto Político Pedagógico (PPP) mais consistente, os materiais distribuídos pelas empresas ficam em segundo plano, mas quando o projeto da escola é frágil, a escola absorve os materiais. Ela também comentou que os movimentos sociais da comunidade têm sido críticos às parcerias entre empresas e escolas. Uma possível contribuição das pesquisas que focam suas análises no contexto escolar poderia ser a de investigar como esse movimento está impactando a escola, considerando a necessidade de ouvir a comunidade escolar sobre que valores são transmitidos, qual (is) concepção (ões) de EA está (ão) presente (s) nos programas, que temas são trabalhados e, sobretudo, identificar de que forma os projetos impactam os eixos assinalados pela pesquisa $\mathrm{O}$ que fazem as escolas que dizem que fazem Educação Ambiental?

O terceiro grupo a se apresentar levantou a necessidade de investir na parceria entre escolas e universidades. Para seus integrantes, as parcerias público-privadas podem ser positivas se não se configurarem em apropriação do espaço escolar voltada para interesses específicos. Ao afirmarem que as empresas poderiam ajudar com recursos para que as escolas desenvolvam seus próprios projetos, foram questionadas 
sobre o interesse que as empresas teriam em ajudar as escolas sem retorno para seus negócios. Em resposta à questão, os integrantes do grupo argumentaram que se a parceria for realmente uma parceria, isso pode acontecer. A contribuição do grupo para o enfrentamento das questões colocadas se dá no sentido de pensar sobre as perspectivas de EA nos materiais didáticos.

O debate trazido pelo quarto grupo girou em torno de relatos sobre o Pontal do Paranapanema (SP), onde três usinas de beneficiamento de cana, de um único dono, dominam o trabalho de EA nas escolas da região. Um de seus membros e autor de trabalho mencionou que a população da cidade e da área de assentamento trabalha na usina, o que dificulta a crítica e a pesquisa sobre os conflitos existentes na região. Para ele, falta aos professores uma visão mais crítica sobre essa realidade. Sua pesquisa é sobre concepções de natureza e meio ambiente dos professores, mas considera que essa questão pode ser aplicada às cartilhas produzidas pelas empresas.

Outra participante do grupo afirmou que, em uma escola de Campinas, existe uma disciplina intitulada Espaços Educadores Sustentáveis, que trabalha com conceitos de água, ar, solo, terra e homem, faz visitas a espaços extraescolares e criou a categoria fiscal de sustentabilidade entre os alunos, que fiscaliza o comportamento sustentável do corpo discente. Um membro da Secretaria de Educação de São Paulo, presente no GDP, afirmou que essa iniciativa é parte do incentivo do governo federal à educação integral. Os coordenadores do GDP ressaltaram a importância dessas realidades serem conhecidas e pesquisadas como contribuição para os estudos sobre EA de tipo escolar, ressaltando que a crítica deve ser feita também em relação à intervenção de ONGs e movimentos sociais nas escolas.

O quinto e último grupo se posicionou em defesa de um programa de formação de educadores ambientais, em contraste com a formação pontual que, observam, está calcada em temas como água, lixo etc. Para o grupo, é preciso discutir o que é Educação Ambiental, que tem uma abordagem muito frágil nas escolas e sujeita a influências externas, sendo uma delas as parcerias público-privadas, que mercantilizam a sustentabilidade. Nesse contexto, as parcerias público-privadas seduzem os professores, reforçando a necessidade de uma formação como política pública que possa contribuir para a construção de um Projeto Político Pedagógico crítico e voltado para os interesses da comunidade. Sobre a questão crítica de quê, o grupo entende que é necessário, primeiramente, um maior entendimento sobre o conceito, enquanto sociedade e relação consumo/necessidade, em contraposição ao capitalismo. Para eles, essa discussão deve ser gerada nas universidades, onde os professores realizam suas formações.

No final do debate, os coordenadores do GDP levantaram o problema do aligeiramento atual das pesquisas, que citam autores ligados à perspectiva crítica, mas a crítica não faz parte da pesquisa. Observa-se a mesma tendência em relação à ideia de sustentabilidade. Por essa razão, a provocação - crítica de quê? - foi trazida para o GDP como uma questão importante para o campo da EA. Eles afirmaram, ainda, que a escola sempre esteve permeável a muitas entradas, e que uma importante questão para investigação é compreender as resistências escolares em relação aos processos de subordinação, que poderiam nos indicar quais são os elementos dessa resistência. Um relato da professora que trabalha na Secretaria de Educação do Estado de São Paulo confirmou essa hipótese: ela mencionou uma escola pública de um município paulista que resiste aos materiais provenientes dessas parcerias e que montou uma estrutura de produção de material didático, com reuniões e encontros entre seus docentes. 


\section{Discussão}

Os debates travados no GDP EA no contexto escolar tiveram desdobramentos importantes: um deles foi a identificação, por parte dos integrantes do grupo, de frutíferas questões para pesquisas, relacionadas aos eixos temáticos norteadores da discussão. Levando-se em conta o perfil dos participantes, consideramos que atingimos um dos nossos principais objetivos, que era o de incentivar e ampliar o rol de temáticas das pesquisas sobre a EA na escola, aproximando-as da perspectiva crítica da educação ambiental. Outro ponto considerado positivo é a confirmação, por parte do grupo, da necessidade do diálogo com autores do campo da educação.

No artigo que escrevemos sobre o GDP de contexto escolar do VI EPEA buscamos compreender as características da educação ambiental como conhecimento escolar, que sofre influência dos campos disciplinares de referência e da Educação Ambiental. Afirmamos que "uma tradição de práticas e temáticas de EA está sendo criada e veiculada nos meios educacionais e acadêmicos, possivelmente auxiliada pelos encontros de 'ensino de' (...) e também pelos Encontros de Pesquisa em EA" (GUIDO; LIMA; CARVALHO, 2012, p. 115). Nessas práticas e temáticas, e a partir da pesquisa $O$ que fazem as escolas que dizem que fazem educação ambiental? (TRAJBER; MENDONÇA, 2006), identificamos potenciais investigações sobre aspectos curriculares, epistemológicos e formativos da EA praticada nas escolas, "que assumem caráter ainda mais central num contexto de produção de políticas e diretrizes curriculares de EA que gera preocupações sobre os rumos da EA nos contextos escolares" (GUIDO, LIMA E CARVALHO, 2012, p. 116).

Em relação às políticas, as diretrizes curriculares nacionais para a educação ambiental (MEC, 2012) determinam, no Art. 14. Inciso 5, que:

[...] a Educação Ambiental nas instituições de ensino, com base nos referenciais apresentados, deve contemplar o estímulo à constituição de instituições de ensino como espaços educadores sustentáveis, integrando proposta curricular, gestão democrática, edificações, tornando-as referências de sustentabilidade socioambiental (grifos nossos).

Os espaços educadores sustentáveis aparecem, também, no Art. 21:

[...] os sistemas de ensino devem promover as condições para que as instituições educacionais constituam-se em espaços educadores sustentáveis, com a intencionalidade de educar para a sustentabilidade socioambiental de suas comunidades, integrando currículos, gestão e edificações em relação equilibrada com o meio ambiente, tornando-se referência para seu território (MEC, 2012, s/p, grifos nossos).

A conversão de escolas em espaços educadores sustentáveis vem sendo alvo de interesse de ONGs e empresas, que buscam parcerias com governos e prefeituras para sua implementação, como aconteceu com a Prefeitura de Piracicaba (SP), que, junto à Escola Superior de Agricultura Luiz de Queiroz (ESALQ/USP) e o Instituto Estre ${ }^{4}$ uma Organização de Sociedade Civil de Interesse Público (OSCIP), implementou o projeto Escolas Sustentáveis na Rede Municipal de Ensino ${ }^{5}$. Essa ONG também produz cadernos conceituais e outros materiais utilizados em oficinas pedagógicas para professores. No sítio eletrônico do Instituto Estre há um link sobre as parcerias

\footnotetext{
${ }^{4}$ Sobre o Instituto Estre: <http://www.institutoestre.com.br/>

5 Mais informações em: <http://www.educacao.piracicaba.sp.gov.br/site/todas-as-noticias/322-secretariade-educacao-de-piracicaba-lanca-o-projeto-escolas-sustentaveis-na-rede-municipal-de-ensino.html> .
} 
estabelecidas: uma delas é com a FDE (Fundação para o Desenvolvimento da Educação do Estado de São Paulo), a partir da qual foi criado o Centro de Educação Ambiental em Paulínia e seu "programa de oficinas pedagógicas para turmas de alunos de escolas estaduais, que virão ao instituto em seu horário de aula". Há, ainda, a informação de que "em cinco anos de atuação (2008/2012), foram investidos mais de 11 milhões de reais nos Programas de Educação Ambiental, Apoio ao Reflorestamento, aumento da infraestrutura e ações institucionais" (INST. ESTRE, 2012). Um aspecto bastante interessante para ser investigado está relacionado com as origens e fontes de financiamento desses projetos, além, é claro, de investigar os reais interesses em investimentos tão altos em programas educativos

Relacionado a esse fato temos que, nas diretrizes curriculares, o termo sustentabilidade aparece nove vezes - seis delas associadas ao adjetivo socioambiental , mas não há nenhuma definição ou delimitação de sentidos para sustentabilidade, ou sustentabilidade socioambiental. Cabe perguntar o que é, afinal, necessário para se considerar uma empresa, ONG, escola ou ação governamental sustentável, quem está apto a dar esse título às instituições e quais são os parâmetros a ser cumpridos. Sem respostas a essas perguntas, o interesse do terceiro setor, ou do setor empresarial em criar/construir os tais espaços educadores sustentáveis em um ambiente marcado pela superficialidade conceitual com que são utilizados os termos sustentabilidade ou sustentabilidade socioambiental, favorece a implementação de propostas pouco fundamentadas e, muitas vezes, distantes do projeto da própria escola e nem sempre com transparência em relação aos seus reais patrocinadores. Não basta se autodeclarar sustentável para sê-lo realmente, e, muito menos, para se tornarem sustentáveis com o sentido que muitos de nós vem construindo em relação a esse novo significante.

O exemplo citado é apenas um dentre muitos casos de parcerias público-privadas na educação ${ }^{6}$. Diante da presença cada vez maior do discurso empresarial nos contextos escolares via educação ambiental, consideramos frutífera a indagação sobre a influência desse discurso nos conhecimentos produzidos e veiculados nas escolas, bem como aqueles provenientes de materiais didáticos produzidos pelas empresas. Que diálogos têm se estabelecido entre esses conhecimentos com aqueles, fruto das produções docentes? Em que se assemelham e em quê se diferenciam em cada contexto? Em que extensão os professores, de fato, interagem e se relacionam com eles e os ressignificam? Em que medida essas inciativas são problematizadas, se é que o são, nos cursos de formação de professores?

Trazemos para o debate a contribuição de Plácido e Guimarães (2013), que apresentaram, no VII EPEA, pesquisa sobre as relações estabelecidas a partir de parcerias público-privadas no desenvolvimento de programas de educação ambiental e empresarial no contexto escolar. Segundo os autores, a globalização intensificada nos anos de 1990 levou ao entendimento, por alguns setores da sociedade, que a educação escolar é uma via fundamental para o desenvolvimento econômico. Essa crença se materializou por meio de projetos, metas e planos, e uma de suas formas mais eficientes de consolidação são as políticas públicas, que têm incentivado a intervenção do setor empresarial na escola pública através de mecanismos como a lei a Lei de Incentivos Fiscais. Nesse contexto, as parcerias se convertem em instrumentos de marketing das empresas e como forma de assegurar sua legitimidade. A partir daí, surge o conceito ou ideia de responsabilidade social, ou responsabilidade socioambiental.

\footnotetext{
${ }^{6}$ Em Lamosa (2010) e Loureiro e Lima (2012) outros exemplos são apresentados.
} 
Plácido e Guimarães (2013, p.11) concluem que essa relação empresa-escola a partir da Educação Ambiental constitui-se em um movimento de hegemonização de concepções de Educação Ambiental "afinadas com as correntes da ecoeficiência, centrando a solução da problemática ambiental na esfera das tecnologias, da eficiência e das ações individualizadas, desconectadas do todo", com pouca ou nenhuma participação dos educadores e educandos na elaboração e na reelaboração dos projetos propostos. Nessa relação nada dialógica, os materiais didáticos produzidos pelas assessorias pedagógicas das empresas chegam às escolas impregnadas de discurso empresarial, fazendo da escola uma via de transmissão de valores capitalistas, mediados pelo setor empresarial.

Nessa mesma linha, Bagnolo (2013) buscou compreender como as escolas da rede municipal de ensino de Mogi-Guaçu (SP) interagem com as diferentes ações empresariais voltadas à prática de Educação Ambiental na escola. A autora identificou um posicionamento permissivo frente às investidas empresariais, aliado à carência material e de formação para lidar com a temática ambiental na escola. Esse trabalho, também apresentado no VII EPEA, é um recorte da pesquisa de doutorado da autora.

Embutida nessa discussão está a carência de investimentos em políticas públicas voltadas para a formação de professores em EA, levantada por um dos grupos. Evidente está que os investimentos públicos em formação estão sendo direcionados para empresas, ONG ou OSCIPS. Suspeitamos que esses investimentos no setor privado ou no terceiro setor estão diretamente relacionados à incipiente articulação das redes de educação básica com instituições públicas de ensino e pesquisa e, nesse sentido, sugerimos que sejam levantadas, divulgadas e ampliadas as iniciativas formativas em educação ambiental organizadas por universidades e outras instituições públicas. Não menos importante, nesse contexto de enfrentamento em que nos encontramos, é a extensão universitária, que busca, articulada ao ensino e à pesquisa, aproximar-se dos sujeitos envolvidos com essa problemática para, com eles, identificar questões e construir conhecimentos.

Os limites de espaço nos obrigam a concluir, por ora, essa discussão, não sem antes relatar que percebemos, nos depoimentos do(a)s professore(a)s que participaram do GDP, angústias, dúvidas e inseguranças a respeito do contexto em que realizam seu trabalho. Percebemos, também, uma busca de aproximação com a universidade, vista como meio de compreensão e superação das difíceis e complexas realidades docentes.

Para nós, ficou clara a necessidade de uma maior articulação entre pesquisas educacionais e contextos escolares. A riqueza das questões levantadas nesse encontro não pode se perder em aligeiramentos, simplificações e/ou na correria das nossas vidas acadêmicas e docentes: como professores e pesquisadores em educação, é preciso ouvir, com seriedade, os apelos que esses profissionais nos fazem, ou estaremos nos esquivando à própria função social da Universidade, que não é, nem pode ser, a de gerir publicações, nem de pesquisar por pesquisar. Consideramos que a complexidade e a gravidade das questões que os professores e pesquisadores colocaram a esse GT deve ser enfrentada coletivamente, a partir da reunião de esforços dentro e fora das universidades e escolas, a partir de um programa interinstitucional de pesquisas.

Acrescentamos à discussão as provocações trazidas por Trein (2012), ao criticar a adjetivação de crítica reivindicada por muitos professores e pesquisadores da EA:

Como enfrentar a disciplinaridade da grade curricular, como compatibilizá-la com tempos, vivências, atividades e reflexões atravessadas pelo mundo do trabalho humano em seu permanente intercâmbio com a natureza? $\mathrm{O}$ que, como educadores ambientais, queremos ajudar a construir na escola e fora 
dela, inseridos em um espaço de prática social que não é neutro? Que, historicamente, é constituído por disputas de interesses de toda a ordem e que projeta a formação humana ancorada em uma visão hegemônica de mundo? (TREIN, 2012, p. 315).

Essa autora nos leva a refletir sobre a forma como temos construído conhecimentos sobre a realidade, que leituras de mundo temos feito e em que medida elas se constituem em leituras crítico-reprodutoras ou crítico-transformadoras, no contexto de crise socioambiental em que as práticas educativas estão atravessadas pelo discurso da economia verde e do desenvolvimento sustentável. Essas importantes questões reiteram nossa apreensão em relação aos rumos das pesquisas, que se dizem críticas, em educação ambiental nos contextos escolares, mas que, ao filtrar conflitos e embates acadêmicos e socioambientais e selecionar, sob o manto da sustentabilidade", consensos em torno dos quais não há desacordo, favorece discursos e práticas que não contribuem para a superação das graves realidades que se propõe a enfrentar.

\section{Referências}

BAGNOLO, C.M. A relação empresa-escola e a educação ambiental. In: ENCONTRO PESQUISA EM EDUCAÇÃO AMBIENTAL - EPEA, 7, , 2013, Rio Claro. Anais... Rio Claro: Unesp Rio Claro/Botucatu; USP Ribeirão Preto; UFSCar, 2013. Disponível em: <http://www.epea.tmp.br/epea2013_anais/pdfs/plenary/0060-1.pdf>. Acesso em: 4 jun. 2014.

BAGNOLO, C.M. A pesquisa no campo da formação e do trabalho docente relacionado com a temática ambiental. In CUNHA, A.M.O [et al]. Convergências e tensões no campo da formação e do trabalho docente. Belo Horizonte: Autêntica, 2010. p. 67-88.

CARVALHO, I.C. de M.; FARIAS, C. R. de O. Um balanço da produção científica em educação ambiental de 2001 a 2009 (ANPED, ANPPAS E EPEA). In: REUNIÃO ANUAL DA ANPED, 33, 2010, Caxambu. Anais... São Paulo: ANPED, 2010. Disponível em: <http://www.anped.org.br/33encontro/internas/ver/trabalhos-gt22>. Acesso em 4 jun. 2014.

CAVALARI, R.M.F.; SANTANA, L.C.; CARVALHO, L.M. Concepções de educação e educação ambiental nos trabalhos do I EPEA. Pesquisa em Educação Ambiental, Rio Claro, v. 1, n.1, p. 141-173, 2006.

GUIDO, L. E; LIMA, J. G.; CARVALHO, L. M. Pesquisa em Educação Ambiental no contexto escolar: considerações a partir do GDP. Pesquisa em Educação Ambiental, Rio Claro, v. 7, n. 2, p. 105-118. 2012. Disponível em: <http://www.periodicos.rc.biblioteca.unesp.br/index.php/pesquisa/article/view/6864/4967>. Acesso em: 14 jun. 2014.

Instituto Estre de Responsabilidade Socioambiental. Disponível em: http://www.institutoestre.com.br/instituto. Acesso em 14 de jun. de 2014.

KAWASAKI, C. S. et al. A pesquisa em educação ambiental nos EPEAs (2001 - 2007): natureza dos trabalhos, contextos educacionais e focos temáticos. Pesquisa em Educação Ambiental, Rio Claro, v. 4, n. 2, p. 147-163, 2009. 
LAMOSA, R. de A. C. A Educação Ambiental e o novo padrão de sociabilidade do capital: um estudo nas escolas de Teresópolis (RJ). 2010. Dissertação (Mestrado em Educação) Universidade Federal do Rio de Janeiro. Rio de Janeiro, 2010.

LIMA, J.G.S. de. O que fazem as escolas que fazem Educação Ambiental no Rio de Janeiro? In: REUNIÃO ANUAL DA ANPED, 30, 2007, Caxambu. Anais... São Paulo: ANPED, 2007. Disponível em: <http://www.anped.org.br/reunioes/30ra/trabalhos/GT22-3266-Int.pdf>. Acesso em: 14 jun. 2014

LIMA J. G. S. de A disciplina Educação Ambiental na Rede Municipal de Educação de Armação dos Búzios (RJ): investigando a tensão disciplinaridade/ integração na política curricular. 2011, 240 p. Tese (Doutorado em Educação) - Universidade Federal do Rio de Janeiro. Rio de Janeiro, 2011.

LOUREIRO, C.F.; LIMA, J. G. S. de A hegemonia do discurso empresarial de sustentabilidade nos projetos de educação ambiental no contexto escolar: nova estratégia do capital. Revista Contemporânea de Educação, Rio de Janeiro, v. 7, n. 14, p. 304-318, ago/dez. 2012. Disponível em:

<http://www.revistacontemporanea.fe.ufrj.br/index.php/contemporanea/article/view/405/235 2 . Acesso em: 5 jun. 2014.

LOUREIRO, C. F.; LIMA, J. G. S. de A Educação Ambiental e a escola: uma tentativa de (re) conciliação. In: PAZ, R. J. (Org.). Fundamentos, reflexões e experiências em Educação Ambiental. João Pessoa: Ed. Universitária da UFPB, 2006. Pp. 103-131.

MINISTÉRIO DA EDUCAÇÃO. Conselho Nacional de Educação. Conselho Pleno. Resolução n. 2, de 15 de junho de 2012. Estabelece as Diretrizes Curriculares Nacionais para a Educação Ambiental. Disponível em: 〈http://conferenciainfanto.mec.gov.br/images/pdf/diretrizes.pdf>. Acesso em: 4 jun. 2014.

PLÁCIDO, P. de O.; GUIMARÃES, M. Considerações sobre a relação público-privado: um olhar sobre os programas de educação ambiental empresarial nas escolas. In: ENCONTRO PESQUISA EM EDUCAÇÃO AMBIENTAL - EPEA, 7, 2013, Rio Claro. Anais... Rio Claro: Unesp Rio Claro/Botucatu; USP Ribeirão Preto; UFSCar, 2013. Disponível em: <http://www.epea.tmp.br/epea2013_anais/pdfs/plenary/0021-2.pdf >. Acesso em: 14 jun. 2014.

RINK, J.; Megid Neto, J. Tendências dos artigos apresentados nos Encontros de Pesquisa em Educação Ambiental (EPEA). Educ. Rev., Belo Horizonte, v. 25, n.3, p.235-263, dez., 2009. Disponível em: 〈http://www.scielo.br/pdf/edur/v25n3/12.pdf〉. Acesso em: 12 jun. 2014.

TRAJBER, R.; MENDONCA, P.R. (Orgs.). Educação na diversidade: o que fazem as escolas que dizem que fazem educação ambiental. Brasília: Secretaria de Educação Continuada, Alfabetização e Diversidade, 2006.

TREIN, E. S. A educação ambiental crítica: crítica de que? Revista Contemporânea de Educação,Rio de Janeiro, v. 7, n. 14, p. 304-318, agosto/dez. 2012. Disponível em: <http://www.revistacontemporanea.fe.ufrj.br/index.php/contemporanea/article/view/406/236>. Acesso em: 5 jun. 2014.

Artigo submetido em 20/04/2014 Artigo aprovado em 30/06/2014 